African Crop Science Journal by African Crop Science Society is licensed under a Creative Commons Attribution 3.0 Uganda License. Based on a work at www.ajol.info/ and www.bioline.org.br/cs DOI: https://dx.doi.org/10.4314/acsj.v29i2.1

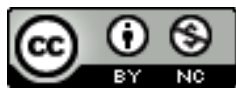

\title{
KARYOTYPIC ANALYSES OF ACCESSIONS OF KERSTING'S GROUNDNUT
}

\author{
I.C. ODO and F.I. AKANEME
}

Department of Plant Science \& Biotechnology, Faculty of Biological Sciences, University of Nigeria, Nsukka, Nigeria

Corresponding author: ifeoma.akaneme@gmail.com

(Received 20 March 2021; accepted 21 April 2021)

\begin{abstract}
Kersting's groundnut (Macrotyloma geocarpa) is an orphan crop of significant food and household income in sub-Saharan Africa. The objective of this study was to evaluate the chromosomal variability among the accessions of the species through analysis of the karyotypes. Six accessions of Kersting's groundnut were subjected to conventional cytological techniques, using root tip meristems. The somatic chromosome number was $2 \mathrm{n}=20$ in all the accessions. The highest total chromosome length was obtained in Tkg $1(1.739 \pm 0.047)$; while the least was in Tkg $12(1.014 \pm 0.029)$. All the accessions had metacentric, submetacentric and subtelocentric chromosomes. However, there was a preponderance towards metacentric chromosomes, suggesting a symmetrical karyotype, which is known to be a primitive condition. Five of the accessions were grouped in karyotype $2 \mathrm{~A}$ while one accession, Tkg 9 was grouped in karyotype $2 \mathrm{~B}$. The $2 \mathrm{~B}$ karyotypes are known to have greater chromosomal asymmetry than 2A; thus Tkg 9 may be advancing evolutionarily faster than the other accessions. Hierarchical cluster analysis divided the accessions into three clusters. Cluster 1 comprised of four accessions (Tkg 1, Tkg 6, Tkg 9 and Tkg 11); while Cluster 2 comprised of one accession (Tkg 6); and cluster 3 had one accession (Tkg 12). Tkg 6 and Tkg 12 were observed to be distantly related to the other accessions; as such could serve as parents in hybridisation programmes to generate wider variability for the improvement of the species.
\end{abstract}

Key Words: Chromosome, hybridisation, Macrotyloma geocarpa, Metacentric

\section{RÉSUMÉ}

L'arachide de Kersting (Macrotyloma geocarpa) est une culture orpheline alimentaire et de revenus significatives des ménages en Afrique Subsaharienne. L'objectif de cette étude était d'évaluer la variabilité chromosomique parmi les accessions de l'espèce en utilisant les analyses des caryotypes. Les six accessions ont été soumises à des techniques cytologiques conventionnelles en utilisant des méristèmes de la pointe des racines. Le nombre de chromosomes somatiques était de $2 \mathrm{n}=20$ dans toutes les accessions. La longueur totale de chromosome la plus élevée a été obtenue en Tkg 1 (1,739 + 0,047); tandis que le moins était en Tkg $12(1,014+0,029)$. Toutes les accessions avaient des chromosomes métacentriques, submétacentriques et subtélocentriques. Cependant, il y avait une 
prépondérance de chromosomes métacentriques, suggérant un caryotype symétrique qui est connu pour être une condition primitive. Cinq des accessions ont été regroupées dans le caryotype $2 \mathrm{~A}$ tandis qu'une accession, Tkg 9 a été regroupée dans le caryotype 2B. Les caryotypes $2 \mathrm{~B}$ sont connus pour avoir une plus grande asymétrie chromosomique que 2A; ainsi Tkg 9 peut évoluer plus vite que les autres accessions. L' analyse hiérarchique des clusters a placé les accessions en trois clusters. Groupe 1 composé de quatre accessions (Tkg 1, Tkg 6, Tkg 9 et Tkg 11); tandis que le groupe 2 comprenait une accession (Tkg 6); et le groupe 3 avait une accession (Tkg 12). On a observé que les Tkg 6 et Tkg 12 étaient éloignées des autres accessions; en tant que tel pourrait servir de parents dans les programmes d'hybridation pour générer une plus grande variabilité pour l'amélioration de l'espèce.

Mots Clés: Chromosome, hybridation, Macrotyloma geocarpa, métacentrique

\section{INTRODUCTION}

Kersting's groundnut (Macrotyloma geocarpa) is an orphan crop of significant food and household income in sub-Saharan Africa (SSA) (Coulibaly, 2020). The plant belongs to the leguminous family Fabaceae (ITIS, 2011) and is cultivated in West Africa, Tanzania, Mauritius and Fiji primarily for its edible seeds (AchiganDako and Vodouhe, 2006). The seeds are richer in amino acids such as lysine and methionine, than most of the other legume crops (Ajayi and Oyetayo, 2009).

The crop is also of immense medicinal importance, being reportedly effective against diarrhoea, poisoning, dysentery, veneral diseases, fever and diabetes (Achigan-Dako and Vodouhe, 2006; Amujoyegbe et al., 2007). Furthermore, the plant plays a role in improving soil fertility in association with nitrogen fixing bacteria of the Bradyrhizobia type (Adazebra, 2013).

According to Amujoyegbe et al. (2007), Kersting's groundnut is on the verge of extinction due to lack of efforts to develop it. Similarly, Adu-Gyamfi et al. (2012) noted that the crop is likely to disappear from the food basket of households in sub-Saharan Africa unless efforts are engineered to rescue it. As of 2006, only 12 accessions were conserved in the seed gene bank of the International Institute of Tropical Agriculture (IITA) Ibadan, Nigeria (Achigan-Dako and Vodouhe, 2006).

Moreover, Ayenan and Ezin (2016) quoting several authors, noted only about 100 accessions conserved in various gene banks in Benin, Ghana, France and Belgium. The authors advocated for extensive characterisation and evaluation of the available germplasm.

According to Achigan-Dako and Vodouhe (2006), little is known about the genetic diversity of $M$. geocarpa and no breeding programmes exist on them; thus there are no improved varieties thus far. In particular, complete knowledge and understanding of the genetic diversity among the available germplasm is necessary as a basis for meaningful development of the crop. Ghafor and Ahmad (2005) earlier reported that information about genetic diversity of germplasm is a useful tool in genebank management and in planning experiments as it assists researchers in identifying and /or eliminating duplicates in the genestock.

Baltisberger and Horandl (2016) and Kawano (2018) are of the opinion that karyotyping is a powerful method for characterising genomes of species. These authors further wrote that karyotypic features are important factors for delineating plant species because chromosomal differences establish immediate postzygotic crossing barriers. In otherwords, species with different karyotypes would not be able to cross; while those with same karyotype would be expected to produce hybrids. The distinctive feature of karyotyping is the ability to differentiate closely related species that have the same chromosome number (Saensouk et al., 2019). 
Prajitha and Thoppil (2018) noted that genetic variability and evolutionary status of the species are indices of survival of a species to changing environmental conditions.

The objective of this study was to provide the first karyotype of this species and to assess the chromosomal variability among the studied accessions.

\section{MATERIALS AND METHODS}

Six accessions of $M$. geocarpa used in this study were obtained from the Genetic Resources Centre of the International Institute of Tropical Agriculture (IITA) Ibadan, Nigeria. The accessions were labelled by IITA as Tkg 1, Tkg 6, Tkg 8, Tkg 9, Tkg 11 and Tkg 12. This karyotypic study was done in the Cytology Laboratory of the Department of Plant Science and Biotechnology, University of Nigeria, Nsukka. Mitotic root tips of the respective accessions were used for the study.

Fifty seeds of each accession were chemically scarified by soaking them in beakers containing 96\% concentrated anhydrous sulphuric acid. This was done for 5 minutes until gradual appearance of small black spots on the surface of the seeds (Garcia et al., 2006). Subsequently, they were rinsed three times with sterile distilled water to ensure maximum removal of the sulphuric acid to avoid local heating that may damage the seeds.

A pinch of white sand was put into six labelled sieves, which were randomly placed on a laboratory bench and the rinsed seeds were placed in respective sieves. Sand was added to assist in the germination process. The sieves were later placed on beakers which were filled with distilled water. The base of the sieves slightly touched water in the beakers so as to keep the sand wet and to avoid drying out of the seeds. As the seeds began to germinate after five days, the roots penetrated through the sieves into the water in the beaker, thereby giving uncontaminated healthy roots.

On the $7^{\text {th }}$ day between 7.30 and $8 \mathrm{am}$, the tap roots $(1-2 \mathrm{~cm})$ of the respective accessions were chopped off using a small scissors and put into beakers containing distilled water to rinse them (From preliminary studies (unpublished) more dividing cells were observed between 7.30 and 8 am). By gentle shaking of the beakers for two minutes, the roots were cleaned off and the water decanted. The root tips (30 for each accession) were placed separately for a minute on blotting papers in other to remove adhering water before pretreatment.

For the pretreatment, $0.05 \%$ colchicine was prepared and poured into six different specimen bottles. Colchicine helps to break spindle fibres and thus arrest cell division at metaphase stage. The seeds were subsequently put into the labelled bottles and left there for 5 hours at the laboratory room temperature ( 25 $\left.{ }^{\circ} \mathrm{C}\right)$. After 5 hours, they were removed and put into beakers and rinsed under running tap water to wash off the pretreatment solution. The excess water on the root tips were blotted off before putting the seeds in Carnoy's fixative solution in labelled specimen bottles, for duration of 24 hours. The fixative consisted of 1:3 glacial acetic acids to absolute alcohol. The fixed root tips were hydrolysed by placing them in $18 \% \mathrm{HCl}$ for 8 minutes. The $\mathrm{HCl}$ was first heated to $60^{\circ} \mathrm{C}$ in a water bath, within 1 hour before placing the root tips in it.

The respective fixed root tips were placed in $2 \%$ aceto -orcein stain and heated on a burner until the stain boiled. The heating process enabled the maceration of root tips, as well as allowing the stain to penetrate into the cells.

With the aid of a scalpel, $2 \mathrm{~mm}$ pieces of the root tips were cut from the hydrolysed root tips and placed on slides, one root tip per slide. The root tips were macerated with the scalpel. The samples were covered using coverslips without enclosing air bubble. A piece of blotting paper was gently used to absorb the excess stain spilling from the sides of the cover slips. By carefully placing the thumb on the cover slip without moving the cover slip, 
the cells were squashed and spread under the cover slip to avoid chromosome overlap.

The slides were viewed under a microscope at $\times 10$, then $\times 40$ and the good and clear stages were viewed under oil immersion $(\times 1000)$ for photomicrography (with Motic camera 2.0 version). At least 10 metaphase plates were examined for the derivation of chromosome numbers, but the measurements of the individual chromosome lengths (short arm and long arm lengths) were obtained from three well spread metaphase plates of each accession and these were taken in microns using the software Karyo-Type 2.0 version.

The arm ratio (AR) (long arm LA/short arm $\mathrm{SA}$ ), the centromeric index, F\% for the estimation of karyotype asymmetry (the short arm length /the length of the chromosome $\times 100$ ) were calculated using the method of Huziwara (1962). Karyotype symmetry nomenclature was determined based on Stebbin's (1971) classification.

The chromosomes were described according to the methods of Levan et al. (1964) who proposed a standard nomenclature for centromeric position as follows: "The chromosome with an arm ratio of 1.0-1.7 = metacentric, 1.7-3.0 = submetacentric, 3.0$7.0=$ subtelocentric". Arm ratios at the borders defining these chromosome types were described according to the method of Baltisberger and Horandl (2016). Thus, the karyotypic formulae were derived from these descriptions and the length of the chromosome arms were used to draw the ideograms.

Hierarchical cluster analysis was performed using Wards Linkage with squared Euclidean distance (SPSS Version 20). Subsequently, a dendrogram was drawn to depict the relationships among the accessions. The data on short arm lengths, long arm lengths and total chromosome lengths were subjected to Analysis of Variance in Completely Randomised Design (CRD). Significant means were separated by using Least Significant difference tests at the probability of $5 \%$.

\section{RESULTS}

The Chromosome number of each of the accessions was found to be $2 \mathrm{n}=20$ (Fig. 1). Table 1 shows that the short arm lengths ranged from $0.374 \mu \mathrm{m}$ for $\mathrm{Tkg} 12$ to 0.717 $\mu \mathrm{m}$ for $\mathrm{Tkg} 1$. There were significant differences $(\mathrm{P}<0.05)$ among the values for the accessions. Tkg 1 exhibited the maximum short arm length but its length did not differ significantly $(\mathrm{P}>0.05)$ from those of $\mathrm{Tkg} 8$ and Tkg 11. The least short arm length was displayed by Tkg 12 and it differed significantly from those of the other accessions.

The long arm length ranged from 0.640 $\mu \mathrm{m}$ for Tkg 12 to $1.022 \mu \mathrm{m}$ for Tkg 1 (Table 1). There were also significant differences among the lengths for the various accessions $(\mathrm{P}<0.05)$. Tkg 1 again exhibited maximum long arm length but its length did not differ significantly from those of Tkg 8, 9 and 11 . The least long arm length was displayed by Tkg 12 and it differed significantly from all the other accessions.

The longest total chromosome length was shown by Tkg 1 but this did not differ significantly $(\mathrm{P}>0.05)$ from those of Tkg 8 and Tkg 11. On the other hand, Tkg 12 had the least total chromosome length, which differed significantly from those of the other accessions (Table 1).

Arm ratios ranged from 1.00 up to 3.00 for Tkg 1 and 1.00 up to 5.00 for Tkg 6, 8, 9, 11 and 12 (Table 1). Centromeric index or F\% varied from 16.67 up to $50 \%$ for $\mathrm{Tkg} 11$ and 25 up to $50 \%$ for $\mathrm{Tkg} 1$. On the other hand, Total Form percent (TF\%) varied from $37 \%$ (Tkg 6 and $\mathrm{Tkg} 12$ ) to $42 \%$ (Tkg 1) (Table 2).

In terms of Stebbin's Asymmetry (Table 2), five accessions (Tkg 1, 6, 8, 11 and 12) were classified as $2 \mathrm{~A}$; while only one accession (Tkg 9) was classified as 2B. Phylogenetic relationships were depicted in a dendrogram with three clusters of accessions recognised. Cluster 1 comprised of $\mathrm{Tkg} 1,8,9$ and 11; 

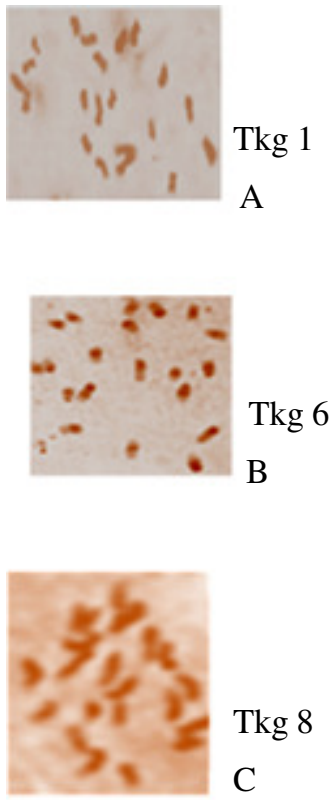
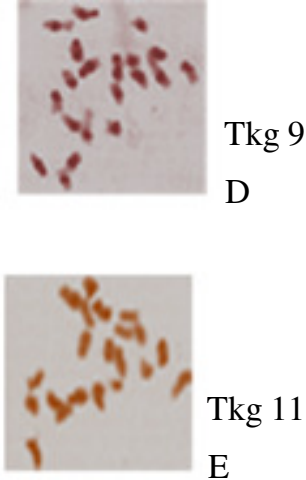

$\mathrm{E}$

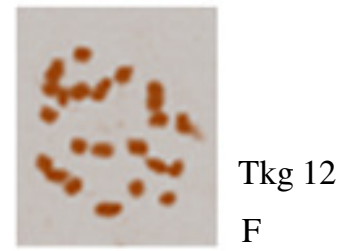

Figure 1. The metaphase plates of Macrotyloma geocarpa $(\times 1000)(2 n=20)$.

TABLE 1. Chromosomal characteristics of six accessions of Macrotyloma geocarpa

\begin{tabular}{lccccc}
\hline Accessions & $\begin{array}{c}\text { Mean short } \\
\text { arm lengths } \\
(\mu \mathrm{m})\end{array}$ & $\begin{array}{c}\text { Mean long } \\
\text { arm lengths } \\
(\mu \mathrm{m})\end{array}$ & $\begin{array}{c}\text { Mean total } \\
\text { chromosome } \\
(\mu \mathrm{m})\end{array}$ & $\begin{array}{l}\text { Range of total } \\
\text { chromosome lengths } \\
(\mu \mathrm{m})\end{array}$ & $\begin{array}{c}\text { Range of } \\
\text { arm ratios }\end{array}$ \\
\hline Tkg 1 & $0.717 \pm 0.034$ & $1.022 \pm 0.048$ & $1.739 \pm 0.047$ & $1.19 \pm 0.012-2.00 \pm 0.003$ & $1.00-3.00$ \\
Tkg 6 & $0.534 \pm 0.040$ & $0.863 \pm 0.036$ & $1.397 \pm 0.054$ & $1.10 \pm 0.003-1.83 \pm 0.005$ & $1.08-5.00$ \\
Tkg 8 & $0.668 \pm 0.046$ & $1.006 \pm 0.036$ & $1.674 \pm 0.063$ & $1.00 \pm 0.003-2.00 \pm 0.003$ & $1.00-4.14$ \\
Tkg 9 & $0.603 \pm 0.035$ & $0.978 \pm 0.049$ & $1.581 \pm 0.071$ & $0.85 \pm 0.012-2.00 \pm 0.003$ & $1.25-3.25$ \\
Tkg 11 & $0.647 \pm 0.043$ & $0.988 \pm 0.047$ & $1.635 \pm 0.059$ & $1.00 \pm 0.003-2.00 \pm 0.000$ & $1.00-5.00$ \\
Tkg 12 & $0.374 \pm 0.015$ & $0.640 \pm 0.037$ & $1.014 \pm 0.029$ & $0.85 \pm 0.012-1.25 \pm 0.003$ & $1.00-4.00$ \\
& & & & & \\
LSD $(0.05)$ & 0.103 & 0.120 & 0.155 & & \\
CV $(\%)$ & 34.2 & 25.6 & 20.2 & & \\
\hline
\end{tabular}

while Cluster 2 had only one accession, Tkg 6 , cluster 3 also one accession, Tkg 12 .

The Karyotypic formulae are shown on Table 2. The chromosomes of each of the accessions consisted of more of metacentrics and few submetacentric and subtelocentrics. The metaphase plates of each of the accessions are shown in Figure 1; while the ideograms are shown in Figures 2 to 7.

\section{DISCUSSION}

This karyotypic study has shown clear evidence that the studied M. geocarpa is diploid with a somatic chromosome number of $2 \mathrm{n}=$ 20 (Fig. 1). This observation is in agreement with an earlier report of Pasquet et al. (2002) who revealed a count of $2 n=20$ for the wild taxon; while Miege (1962) gave a count of $2 n$ 
TABLE 2. Karyotypic features of six accessions of Macrotyloma geocarpa

\begin{tabular}{lcccl}
\hline Accessions & $\begin{array}{c}\text { Range of F } \\
(\mathrm{CI})\end{array}$ & TF $\%$ & $\begin{array}{l}\text { Stebbin's } \\
\text { Asymmetry }\end{array}$ & Karyotype formulae \\
\hline Tkg 1 & $25.00-50.00$ & 42 & $2 \mathrm{~A}$ & $2 \mathrm{n}=20=7 \mathrm{~m}+1 \mathrm{~m} / \mathrm{sm}+2 \mathrm{sm} / \mathrm{st}$ \\
Tkg 6 & $16.67-48.15$ & 37 & $2 \mathrm{~A}$ & $2 \mathrm{n}=20=6 \mathrm{~m}+2 \mathrm{sm}+2 \mathrm{st}$ \\
Tkg 8 & $19.44-50.00$ & 40 & $2 \mathrm{~A}$ & $2 \mathrm{n}=20=7 \mathrm{~m}+1 \mathrm{sm}+1 \mathrm{sm} / \mathrm{st}+1 \mathrm{st}$ \\
Tkg 9 & $23.53-44.44$ & 38 & $2 \mathrm{~B}$ & $2 \mathrm{n}=20=7 \mathrm{~m}+1 \mathrm{sm}+1 \mathrm{sm} / \mathrm{st}+1 \mathrm{st}$ \\
Tkg 11 & $16.67-50.00$ & 40 & $2 \mathrm{~A}$ & $2 \mathrm{n}=20=7 \mathrm{~m}+2 \mathrm{sm} / \mathrm{st}+1 \mathrm{st}$ \\
Tkg 12 & $20.00-50.00$ & 37 & $2 \mathrm{~A}$ & $2 \mathrm{n}=20=6 \mathrm{~m}+2 \mathrm{sm}+2 \mathrm{st}$ \\
\hline
\end{tabular}

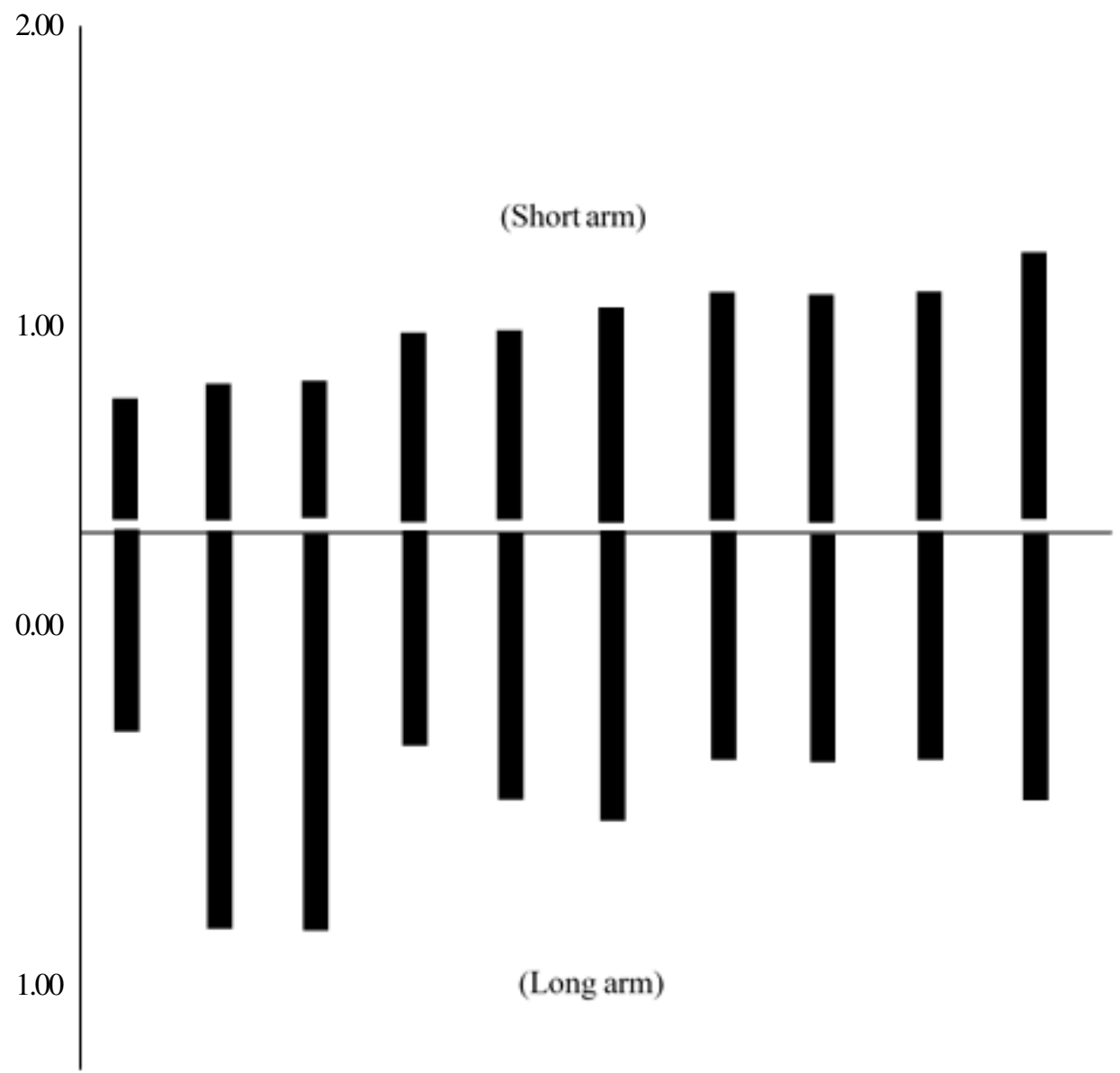

Figure 2. The ideogram of Tkg 1 representing diagrammatically its chromosomes with the aim of showing their relative sizes. The line separating the short and long arms represent the centromere. 


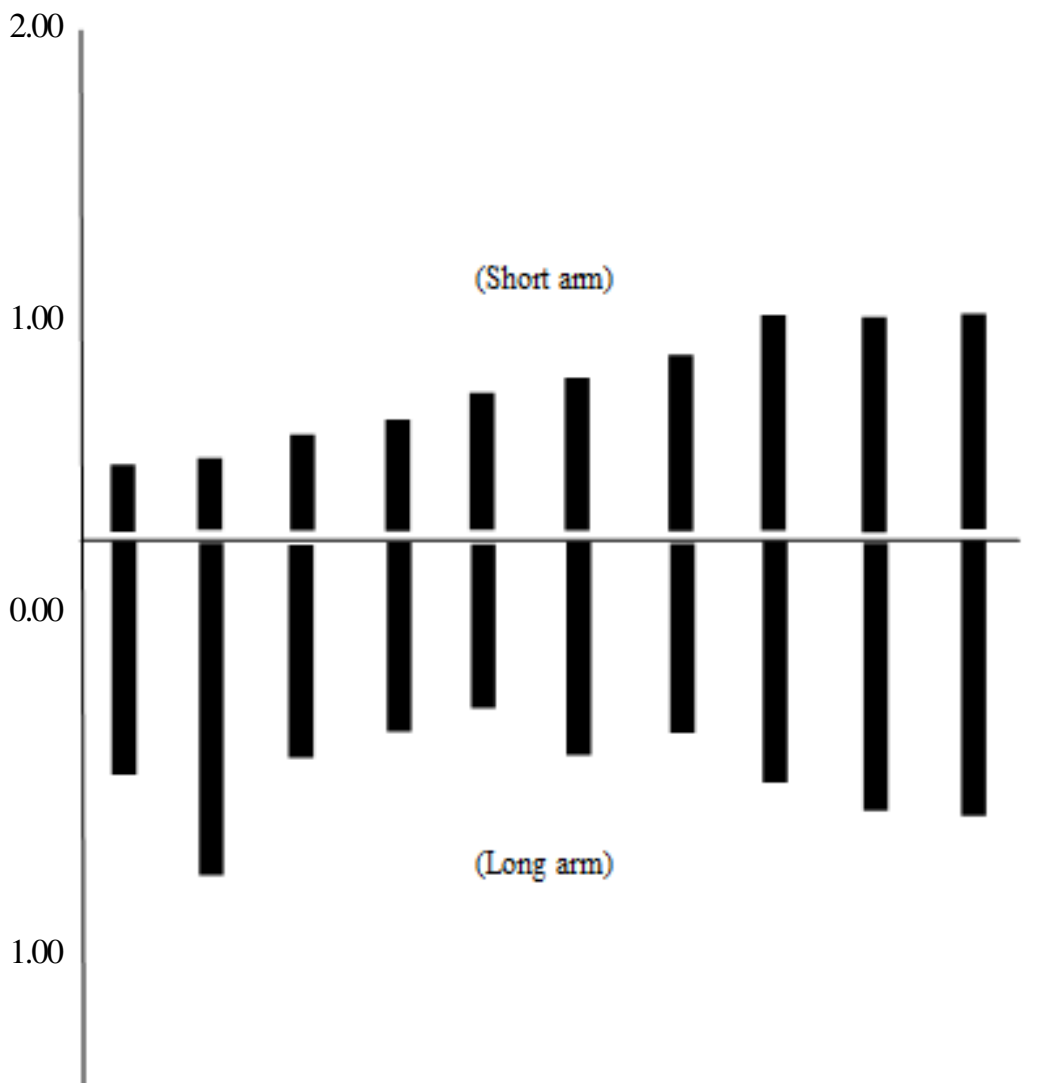

Figure 3. The ideogram of Tkg 6 representing diagrammatically its chromosomes with the aim of showing their relative sizes. The line separating the short and long arms represent the centromere.

$=22$ for the domesticated taxon. Cook et al. (2005) cited in Morris (2008) reported that $M$. axillare has a diploid chromosome number of $2 \mathrm{n}=20$; while $M$. uniflorum has a diploid number of $2 \mathrm{n}=20,22,24$. Halder et al. (2012) confirmed a diploid chromosome number of $2 n=20$ for $M$. uniflorum. The positive implication of these reports for the improvement of $M$. geocarpa is the possibility of successful hybridisation among the accessions since they all had the same chromosome number. Regular chromosome pairing and bivalent formation at meiosis are expected, thus assuring successful hybrid formation as well as hybrid fertility.

There is also the likelihood of successful interspecific hybridisations between $M$. geocarpa and $M$. axillare, and $M$. uniflorum of $2 n=20$. Interspecific crossing assures the introgression of useful traits such as environmental stress tolerance, disease resistance, yield and quality increases in addition to the overcoming of certain agricultural deficiencies (Pink and Keane, 1993; Cao and Deng, 2014).

Uguru et al. (2002) noted that information on the chromosome number of a species can only be of value when considered in conjunction with information on the morphology of the chromosomes as these might show some variations. This fact was authenticated by the report of Seiji and Fernandez (2003) that large differences in chromosome size played a very significant role in the evolution of Lathyrus species, inspite of the stability in chromosome number. Uguru et al. (2002) further noted that, in spite of observable morphological differences in 


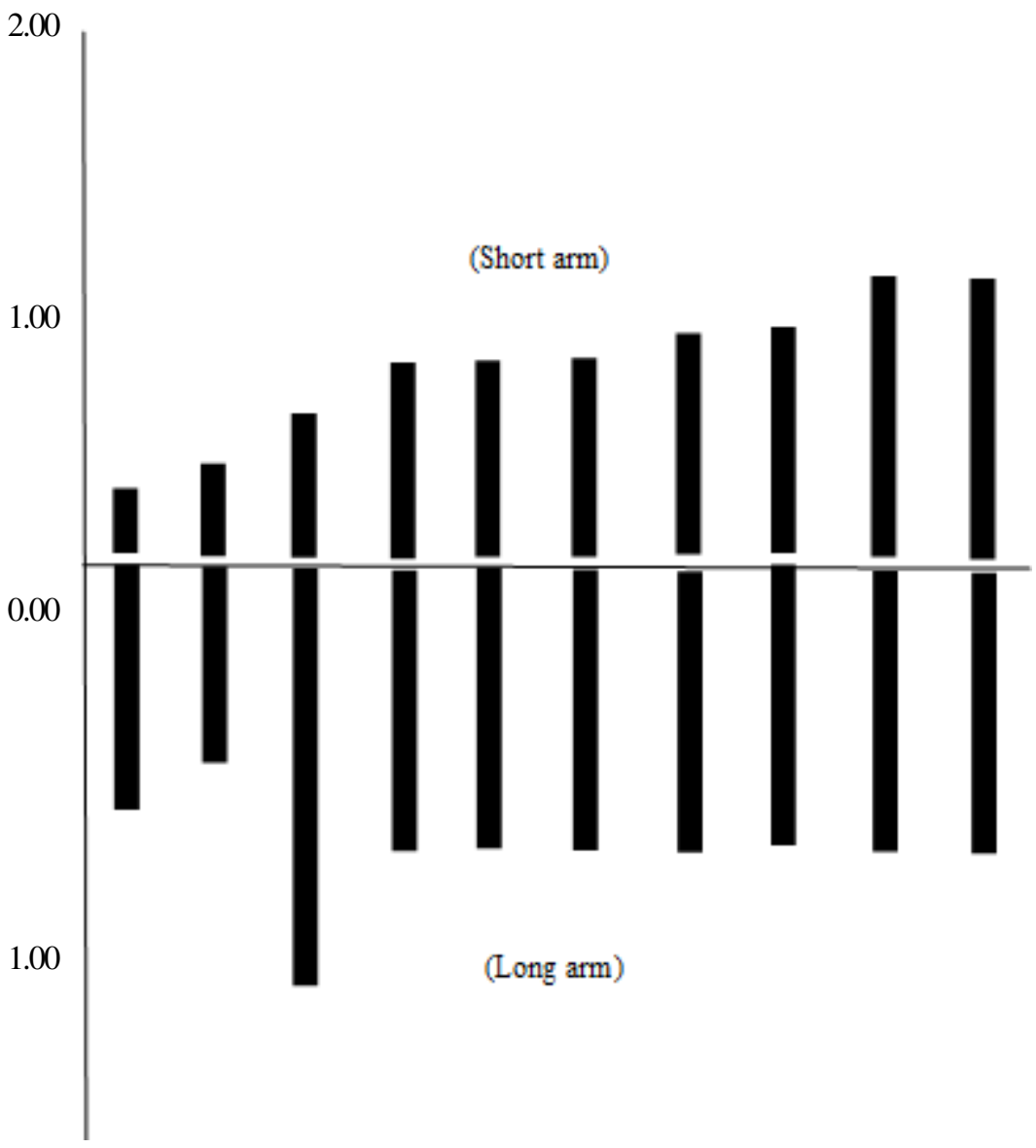

Figure 4. The ideogram of Tkg 8 representing diagrammatically its chromosomes with the aim of showing their relative sizes. The line separating the short and long arms represent the centromere.

chromosomes of genotypes of a species, the occurrence of uniform chromosome number indicates that such genotypes may have evolved from a common ancestor. Archna et al. (2013) reported that possession of same chromosome number and different karyotypic features are indications of ongoing evolutionary processes at microlevel. The uniform chromosome number observed among the accessions of $M$. geocarpa suggest the possibility of evolution from a common ancestor. This fact further gives the assurance of possible successful hybridisations among them since they would share a number of components of chromosomal morphology.

Analysis of the karyotype which was done for the first time in $M$. geocarpa revealed some interesting features that are similar to some related species (Tables 1 and 2). The total chromosome lengths ranged from $0.85-2.00$ $\mu \mathrm{m}$ and this is quite similar to the findings of Halder et al. (2012) in M. uniflorum who recorded a range of $1.26-2.41 \mu \mathrm{m}$. These chromosomal lengths are quite close to those of Phaseolus spp, which had the average range of 0.70 to $1.60 \mu \mathrm{m}$ as recorded by MercadoRuaro and Alfonso (2009). All these ranges, however, are quite small when compared to the range of chromosomes of the most related species such as Bambara groundnut reported with a range of 1.5 to $4.0 \mu \mathrm{m}$. These facts authenticate Uguru et al.'s (2002) earlier assertion that both the chromosome number and chromosome morphology should be taken 


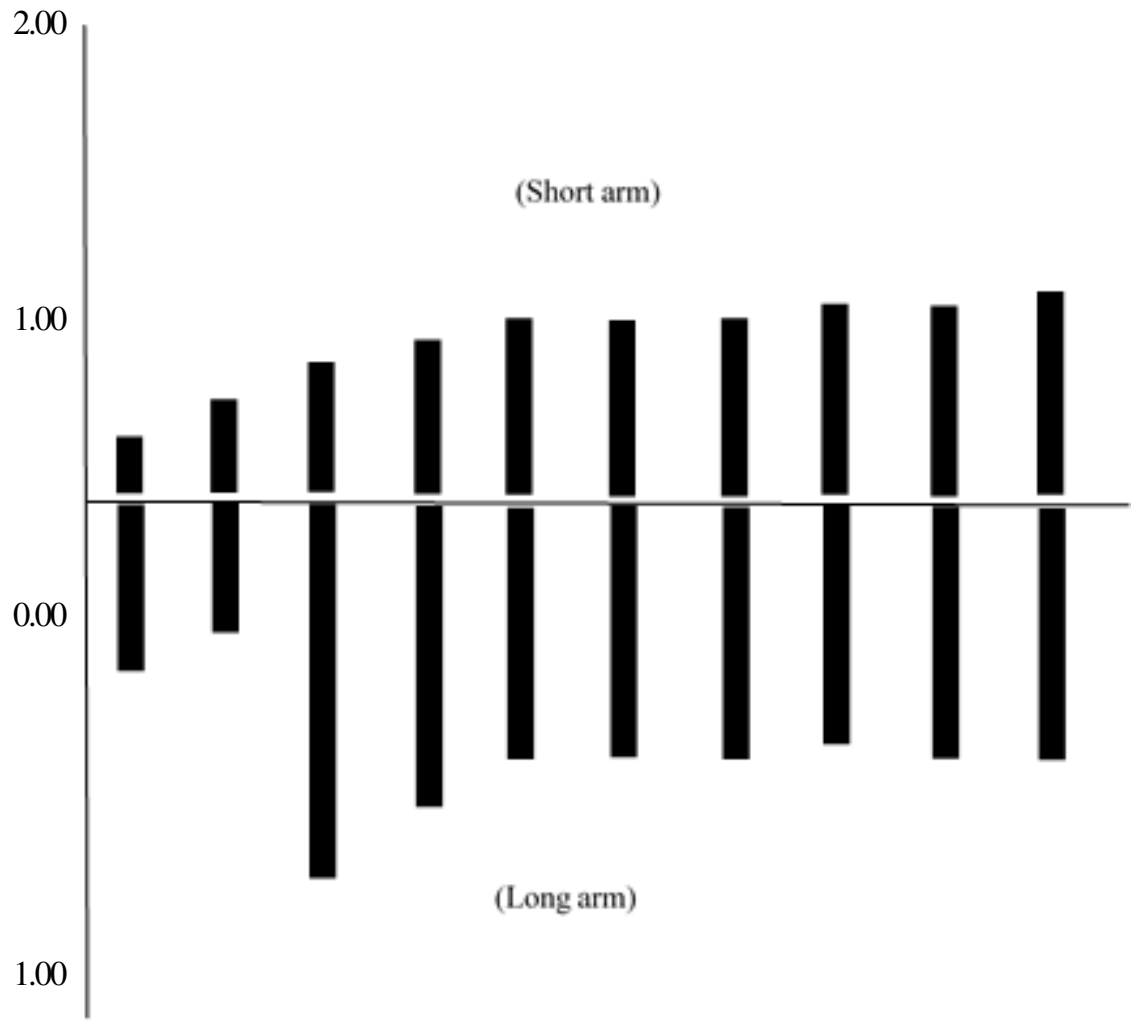

Figure 5. The ideogram of Tkg 9 representing diagrammatically its chromosomes with the aim of showing their relative sizes. The line separating the short and long arms represent the centromere.

into consideration in making breeding decisions. Significant variations in chromosome lengths could pose chromosomal cross over barriers among these species especially among Bambara groundnut (Vigna subterranean) and M. geocarpa, M. uniflorum and Phaseolus species.

The highest total chromosome lengths were observed in $\mathrm{Tkg} 1$ and Tkg 8; while the least total lengths were observed in Tkg 12. Kiran (2018) noted that chromosome length is an indirect indicator of the total DNA amount. Thus, longer chromosomes like those of Tkg 1 and Tkg 8 could have more DNA contents than the smaller chromosomes of Tkg 12 . Uguru et al. (2002) citing Stebbins (1971) reported that longer chromosomes are primitive; while shorter chromosomes are more advanced. Chromosomal size differences among species can arise due to differences in the repetitive DNA sequences (Schmidt et al. 1998 cited in Agbo and Ukwu, 2010). It appears that in the course of evolution, Tkg 12 may have lost some chromosomal segments and ended up having the smallest total chromosome length among the Kersting's groundnut accessions. This view is in tandem with that of Weiss-Schneeweiss and Schneeweiss (2013); who listed factors that lead to changes in karyotype asymmetry to include modifications in chromosome size and morphology. According to them, these modifications can arise as a result of DNA sequence expansions or deletions or due to centric fusions/fissions.

Loureiro et al. (2010) further reported that inter- and intra-specific genome size variation can reveal taxonomic heterogeneity and incipient speciation. The significant differences between Tkg 12 and the other accessions with 


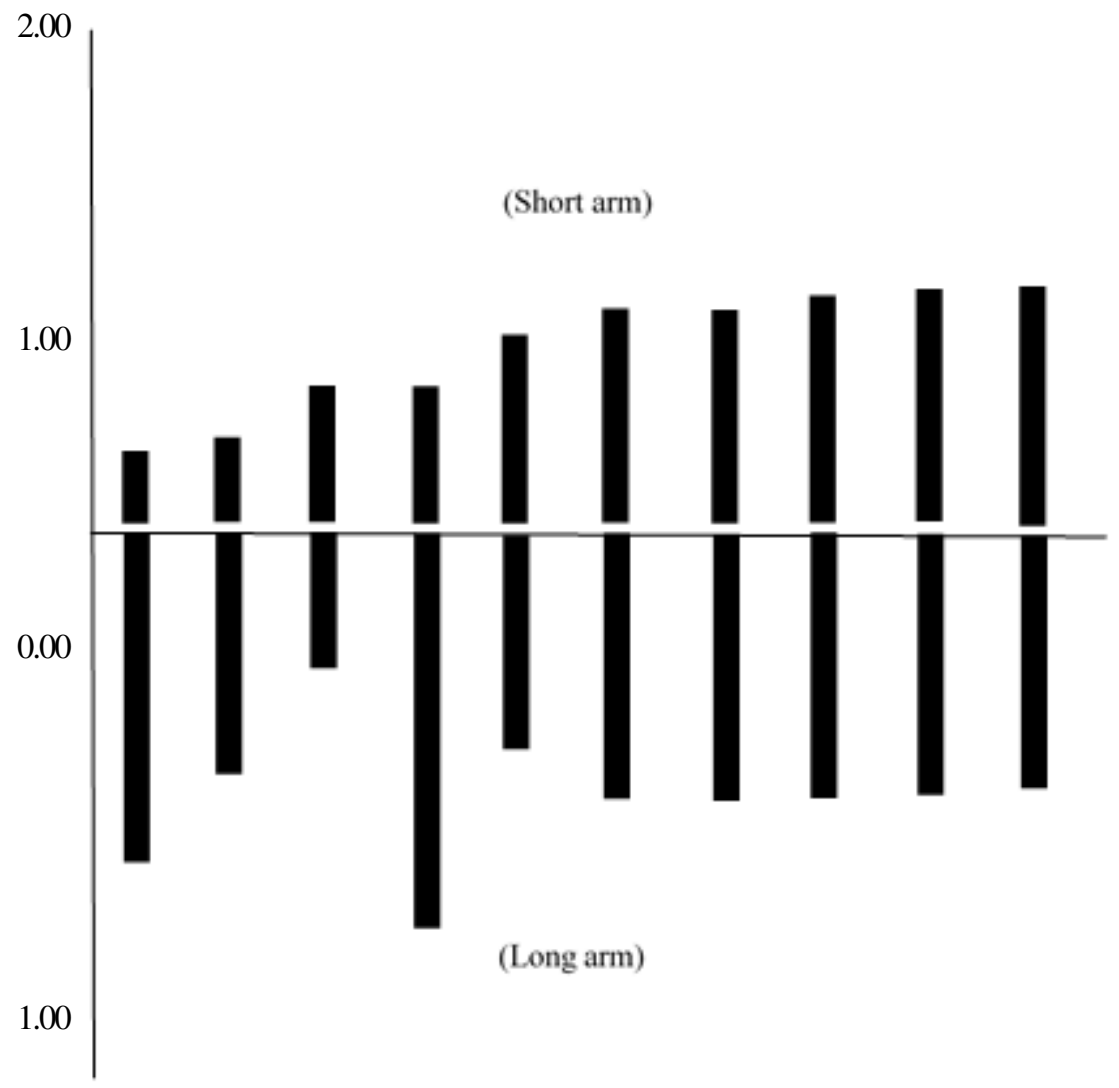

Figure 6. The ideogram of Tkg 11 representing diagrammatically its chromosomes with the aim of showing their relative sizes. The line separating the short and long arms represent the centromere.

respect to short arm length, long arm length and total chromosome length is a pointer to some evolutionary processes going on at microlevel in $\mathrm{Tkg}$ 12, as earlier observed by Archna et al. (2013). The resolution of this fact awaits the employment of more advanced cytological techniques in the study of the chromosomes of this species.

Yang et al. (2015) from earlier literature, revealed that karyotype evolution proceeds from symmetry to asymmetry in higher plants and based on this fact, karyotypes were classified into 12 types which depicted increasing asymmetry viz: $1 \mathrm{~A}-4 \mathrm{~A}, 1 \mathrm{~B}-4 \mathrm{~B}$, and $1 \mathrm{C}-4 \mathrm{C}$. The authors further noted that symmetric karyotypes are characteristic of primitive plants while asymmetric karyotypes are found in more evolutionarily advanced taxa. Five of the accessions studied in this work were grouped into karyotype 2A; while one, Tkg 9 was grouped into karyotype 2B (Table 2). Yang et al. (2015) and Liu and Luo (2019) observed that karyotypes of 2A have higher intrachromosomal symmetry (more primitive) than those of $2 \mathrm{~B}$. Therefore, Tkg 9 has higher chromosomal asymmetry than the other accessions and is perhaps advancing evolutionarily faster than them. There appears to be an association between asymmetrical karyotype of Tkg 9 and its shorter total chromosome length as was observed by Mousavi et al. (2013) on Iranian lettuce. This tends to justify Uguru et al. (2002) statement that shorter chromosomes are more advanced; thus providing further evidence of Tkg 9 being more advanced than the other accessions.

In spite of the differences in the ranges of the F\% values, all the accessions of $M$. 


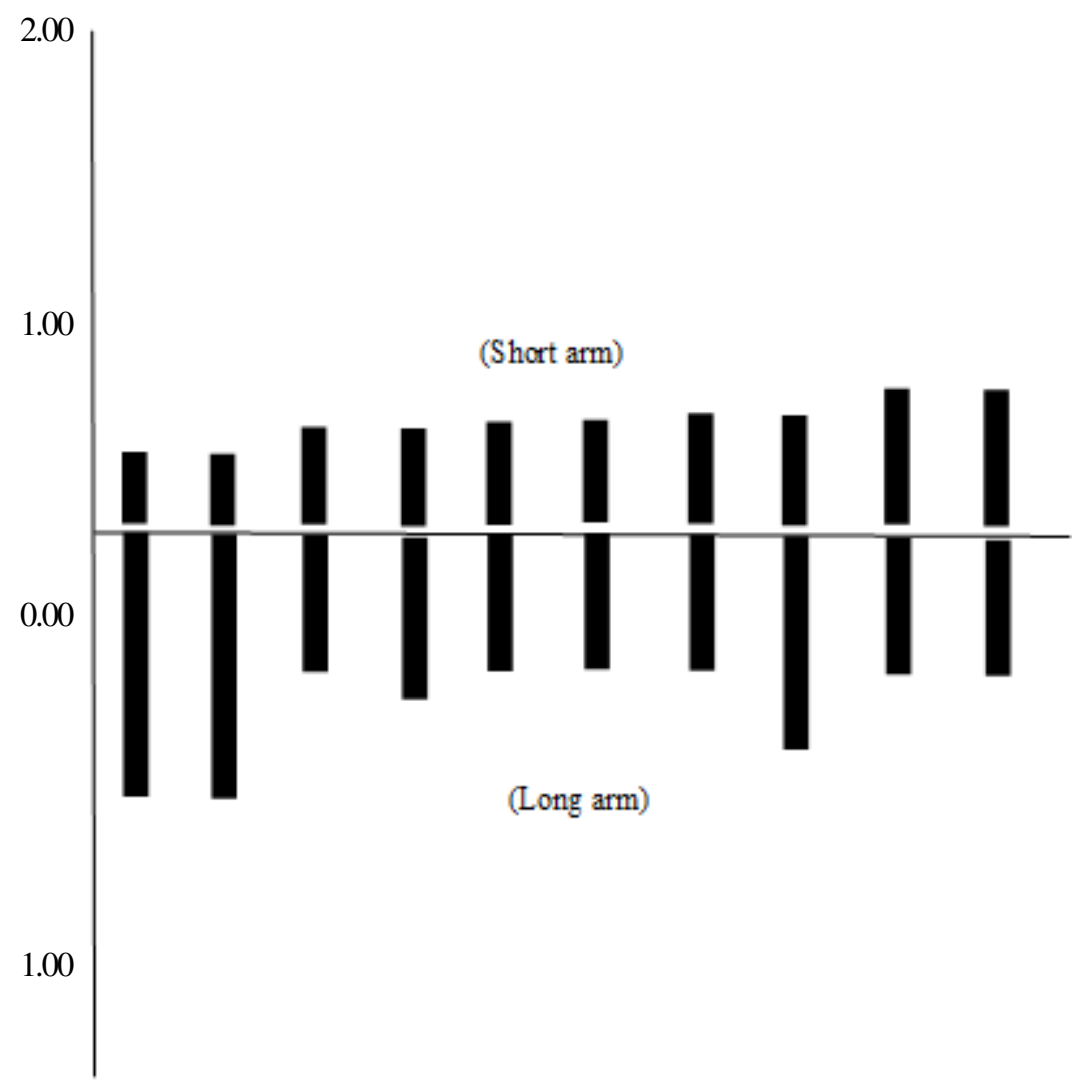

Figure 7. The ideogram of Tkg 12 representing diagrammatically its chromosomes with the aim of showing their relative sizes. The line separating the short and long arms represent the centromere.

geocarpa had metacentric, submetacentric and subtelocentric chromosomes (Table 2). However, there was a preponderance of metacentric chromosomes which was also observed by Halder et al. (2012) on $M$. uniflorum. Agbo and Ukwu (2010) suggested that the preponderance of metacentric and submetacentric chromosomes in G. latifolia indicated that the clones were still evolving and so by extension, $M$. geocarpa accessions can be presumed to be still evolving. The TF\% values in this study were high and according to Archna et al. (2013), such high values represent a high symmetric karyotype which is a primitive condition. A symmetrical karyotype (Lakshmanan et al., 2015) mainly possesses metacentric and submetacentric chromosomes of approximate equal sizes whereas asymmetrical karyotypes arise by shifts in centromeric position towards the telomere. Kersting's groundnut accessions used in this study had symmetric karyotype, but with increasing traces of asymmetry as could be seen in the presence of subtelocentric chromosomes. This shows a gradual shift of the centromere towards the telomere.

The subtelocentrics could have arisen because of deletions and subsequent size reduction of one of the chromosome arms (Uguru et al., 2002). The effect of this would be the shifting of the position of the centromere thus leading to a reduction in the absolute size of the chromosome. This conclusion was earlier drawn by Uguru et al. (2002) on Bambara groundnut and Nejatzadeh-Barandozi and Akbari (2013) on Aloe species. Other factors that could lead to increase in asymmetry are unequal translocations, 
Distance

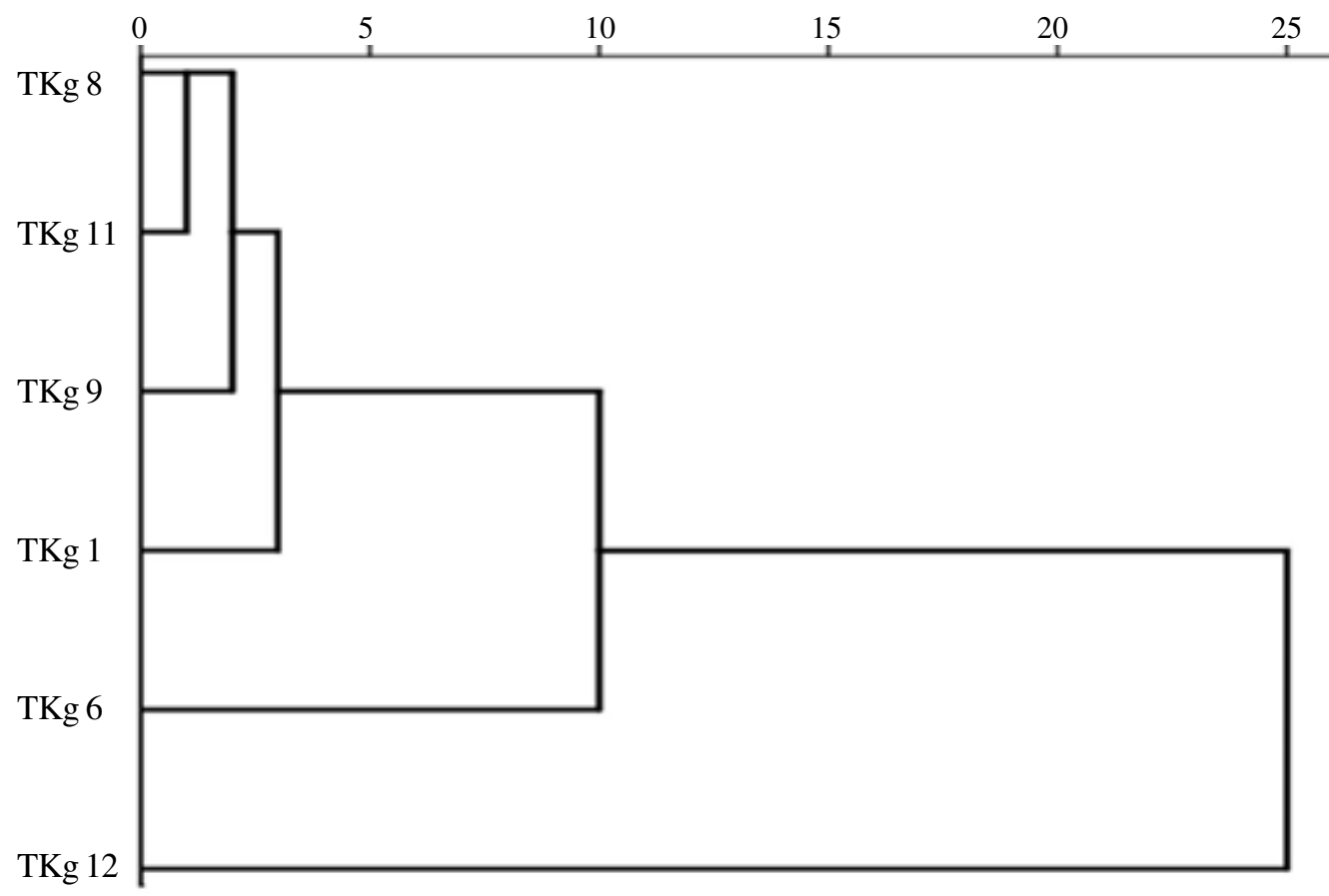

Figure 8. Dendrogram depicting relationships among the six accessions of Macrotyloma geocarpa.

inversions, polyploidisation with possible genome downsizing (Baltisberger and Horandl, 2016; Martin et al., 2020). All these changes in the characteristics of a genome are often presumed to be associated with the evolution of advanced plants as was reported by Sirin $e t$ al. (2019). These may have been occurring in Kersting's groundnut accessions in spite of all of them having the same chromosome number. Macrotyloma geocarpa accessions can therefore, be said to be evolving gradually from symmetrical (primitive) condition to increasing asymmetry (advanced lines).

Clustering observed in the dendrogram (Fig. 8) could indicate close genetic proximity or relatedness. Accessions Tkg 1, Tkg 8, Tkg 9 and Tkg 11 in cluster 1 appear to be closely related. Relative closeness could be due to seed exchanges among farmers in different regions (Yi et al., 2008). Accessions Tkg 6 and Tkg 12 are not closely related to the other accessions and could create wider variations when crossed with them. This fact had earlier been noted by Maity et al. (2009), who reported that identification of parents for hybridisation programmes could be on the basis of distance among accessions in different clusters. Using such distantly related accessions could result in generation of wider variability which is a prerequisite for crop improvement programmes.

\section{CONCLUSION}

All the Kersting's groundnut accessions used in this study have the same chromosome number likely due to their origin from a common ancestor. Morphologically, metacentric, submetacentric and subtelocentic chromosomes are evident in all accessions although, there is a preponderance of metacentric chromosomes suggesting a symmetrical karyotype which is known to be a primitive condition. The presence of few subtelocentrics is an indication of evolutionary advancement towards asymmetry. Tkg 6 and 
Tkg 12 are shown through hierarchical cluster analysis to be distantly related to the other accessions and so could serve as parents in hybridisation programmes to generate wider variability for the improvement of the species. Thus, this study has revealed that some chromosomal variability exist among the accessions of Kersting's groundnut.

\section{REFERENCES}

Achigan-Dako, E.G and Vodouhe, S.R. 2006. Macrotyloma geocarpum (Harms) Marechal \& Baudet. In: Brink, M. and Belay, G. (Eds.). Plant Resources of Tropical Africa 1. Cereals and pulses. PROTA Foundation, Wageningen, Netherlands/ Backhuys Publishers, Leiden, Netherlands/ CTA, Wageningen, Netherlands. pp. 99 102.

Adazebra, G.A. 2013. Yield, quality and nodulation studies of kerstings groundnut in the coastal savannah agro-ecological zone of Ghana. M.Phil. Thesis, Department of Nuclear Agriculture and Radiation Processing, University of Ghana, Legon, Ghana. 90pp.

Adu-Gyamfi, R., Dzomeku, I.K. and Lard, J. 2012. Evaluation of growth and yield potential of genotypes of kersting's groundnut Macrotyloma geocarpum harms) in Northern Ghana. International Research Journal of Agricultural Science and Soil Science 2(12):509-515.

Agbo, C.U and Ukwu, N.U. 2010. Morphology and chromosome numbers of Gongronema latifolia Benth. Clones from Nigeria. African Crop Science Journal 19(1):29- 38.

Ajayi, O.B. and Oyetayo, F.L. 2009. Pontentials of Kerstingiella geocarpa as a health food. Journal of Medicinal Food 12(1):184-187.

Amujoyegbe, B.J., Obisesan, I.O., Ajayi, A.O and Aderenti, F.A. 2007. Disappearance of Kersting's groundnut (Macrotyloma geocarpum Harms) in south-western Nigeria. An indicator of genetic erosion. Plant Resource Newsletter 152:45-50.
Archna, Shivnaz, Tandon, N. and Anand. 2013 Somatic chromosomal studies in Ocimum basilicum and $O$. sanctum L. International Journal of Phytomedicine 5:330-340.

Ayenan, M. A. T. and Ezin, V.A. 2016. Potential of Kerstings groundnut (Macrotyloma geocarpum (Harms) Marechal and Baudet) and prospects for its promotion. Agriculture and Food Security 5(10):1-9.

Baltisberger, M. and Horandl, E. 2016. Karyotype evolution supports the molecular phylogeny in the genus Ranunculus (Ranunculaceae). Perspectives in Plant Ecology, Evolution and Systematics 18:114. http://dx.doi.org/10.1016/j.ppees.2015. 11.001

Cao, Z. and Deng, Z. 2014. Interspecific size and chromosome number variation shed new light on species classification and evolution in Caladium. Journal of American Society of Horticultural Science 139(4):449-459.

Coulibaly, M., Agossou, C.O. A., Akohoue, F., Sawadogo, M. and Achigan-Dako, E.G. 2020. Farmers' preferences for genetic resources of Kersting's groundnut [Macrotyloma geocarpum (Harms) Marechal \& Baudet] in the production systems of Burkina Faso and Ghana. Agronomy 10:371. doi:10.3390/agronomy 10030371.

Garcia, J., Barker, G.G. and Journet, E.P. 2006. Seed storage and germination - Medicago truncatula handbook. https: www.noble. org/globalassets/docs/medicago-handbook/ seed-storage-germination.pdf. Accessed on $15^{\text {th }}$ June 2017.

Ghafor, A. and Almad, Z. 2005. Diversity of agronomic traits and total seed protein in black grain Vigna mungo (L.) Hepper. Acta Biologia Cracoviensia series Botanica 47(2):69-75.

Halder, S., Datta, A.K., Mandal, A. and Ghosh, B.K. 2012. Macrotyma uniflorum (Lam) Verde (Leguminosae) - A note on chromosomal studies. Cytologia 77(4): 447-451. 
Huziwara, Y. 1962. Karyotype analysis in some genera of compositae VIII. Further studies on the chromosome. Asher. American Journal of Botany 49:116-119.

Integrated Taxonomic Information System (ITIS). 2011. Macrotyloma geocarpum. Taxonomy and nomenclature. https:// www.itis.gov/servlet/SingleRpt/ SingleRpt\#null

Kawano, S. 2018. Karyotype and Chromosome behavior analyses in three regions of the Indomalayan Realm. Cytologia 83(3):223-228.

Kiran, Y. 2018. Karyological investigation of sixteen cirsium mill. (Asteraceae, Cardueae) Taxa from Turkey. Cytologia 83(4):407-414.

Lakshmanan, P.S., Laere, K.V., Eeckhaut, T., Huylenbroeck, J.V., Backstaele, E.V and Khrustaleva, L. 2015. Karyotype analysis and visualization of 45 SRNA genes using fluorescence in situ hybridization in aroids (Araceae). Compcytogen 9(2):145-160. doi.10.3897/compcytogen.v.9:2.4366.

Levan, A., Fredga, K. and Sandberg, A. 1964. Nomenclature for centromeric position on chromosome. Hereditas 52:201-220.

Liu, J. and Luo, X. 2019. First report of bicolour FISH of Berberis diaphana and B. Soulieana reveals interspecific differences and co-localization of (AGGGTTT) $_{3}$ and Rdna $5 \mathrm{~s}$ in B. diaphana. Hereditas 156:13-20.

Loureiro, J., Travnicek, P., Rauchova, J., Urfus, T., Stech, M., Castro, S. and Suda, J. 2010. The use of flow cytometry in the biosystematics, ecology and population biology of homoploid plants. Preslia 82:321.

Maity, S., Darra, A.K. and Asokeprasun, C. 2009. Seed polymorphism in nine species of Jute (Corchorus, Family Tillaceae). Indian Journal of Science \& Technology 1(1):34-36.

Martin, E., Kahraman, A., Dirmenc, T., Bozkurt, H. and Eroglu, H.E. 2020. Karyotype evolution and new chromosomal data in Erodium: Chromosome alteration, polyploidy, dysploidy and symmetrical karyotypes. Turkish Journal of Botany 44:255-268. doi:10.3906/bot-1912 -1922.

Mercado-Ruaro, P. and Alfonso, D.S. 2009. Karyotypic analysis in six species of Phaseolus L. (Fabaceae). Caryologia 62(3):167-170. doi: 10.1080?00087114. 2004.10589682 .

Miege, J. 1962. Quatrieme liste de nombres chromosomiques d'especes d'Afrique occidentale. Revue de Cytologie et de Biologie Vegetales 24:149-164.

Morris, J.B. 2008. Macrotyloma axillare and M. uniflorum: descriptor analysis, anthocyanin indexes and potential uses. Genetic Resources and Crop Evolution 55: 5-8.

Mousavi, S.H., Hassandokht, M.R., Choukan, R., Ghanbari, A. and Papini, A. 2013. Genetic diversity of Iranian Lettuce (Lactuca sativa L.) accessions revealed by cytological traits. Caryologia 66(1):41- 48. doi:10.1080/00087114.3013.78044.

Nejatzadeh-Barandozi, F. and Akbari, L. 2013. Karyotypic variation of the Aloe vera $\mathrm{L}$. and Aloe littoralis Baker in Iran. Iranian Journal of Biotechnology 11(14): 233- 37. doi:10.5812/ijb.12985.

Pasquet, R.S., Mergal, G. and Baudion, J.P. 2002. Genetic diversity of the African geocarpic legume Kerstings groundnut, Macrotyloma geocarpa (Tribe. Phasoleae: Fabaceae). Biochemical Systematic and Ecology 30:943-952.

Pink, D.A.C and Keane, E.M. 1993. Lettuce: Lactuca sativa In: Genetic importance of vegetable crops. Kalloo, G. and Berfh, B.O. (Eds.). Pergamon, Oxford. pp. 543-571.

Prajitha, V. and Thoppil, J.E. 2018. Cytogenetic characterization of Amaranthus caudatus L. and A. hybridus subsp. Cruentus (L.) Thell. Cytotechnolog 70:95-101. Https://doi.org/10.1007/ s10616-017-0100-9.

Saensouk, S., Saensouk, P. and Senavongse, R. 2019. Karyological study in three 
Thailand species of Colocasia (Araceae). Cytologia 84(2):179-182.

Seiji, J.G. and Fernandez, A. 2003. Karyotype analysis and chromosome evolution in South American species of Lathyrus (Leguminosae). American Journal of Botany 90:980-987.

Sirin, E., Bozkurt, M., Uysal, T. and Ertugrul, K. 2019. Karyomorphological features of Turkish Centaurea (subgenus Cyanus, Asteraceae) species and its taxonomic importance. Turkish Journal of Botany 43: 538-550.

Stebbins, G.L. 1971. Chromosomal evolution in higher plants. Edward Arnold Publishers Limited, London. 462pp.

Uguru, M.I., Agwatu, U.K and Faluyi, J.O. 2002. Cytogenetic studies on bambara groundnut (Vigna subterranea (L.).
Journal of Agriculture, Food, Environment and Extension 3(2):150-159.

Yi, S.S., Jatoi, S.A., Fujunura, T., Yamanaka, S., Watanabe, J. and Watanebe, K.N. 2008. Potential loss of unique genetic diversity in tomatoe landraces by genetic colonization of modern cultivars at a non-centre of origin. Plant Breeding 127:189-196.

Yang, F., Li, L., Rong, E., He, Y., Zhao, X. and $\mathrm{Wu}, \mathrm{Y} .2015$. Karyotype analysis of obtained tetraploid in medicinal plant (Platycodon grandiflorus). Journal of Medicinal Plants Research (9):294-300. doi:10.5897/JMPR2015.5763.

Weiss-Schneeweiss, H. and Schneeweiss, G. 2013. Karyotype diversity and evolutionary trends in Angiosperms. In: Greilhuber, J., Dolezel, J. and Wendel, J.F. (Eds.). Plant Genome Diversity 2:209-230. Springer, Vienna. 